\section{SAT0393 EFFECTIVENESS AND SAFETY OF INFLIXIMAB, GOLIMUMAB AND USTEKINUMAB IN PSORIATIC ARTHRITIS PATIENTS FROM A PROSPECTIVE OBSERVATIONAL REGISTRY}

Proton Rahman ${ }^{1}$, Regan Arendse ${ }^{2}$, Isabelle Fortin ${ }^{3}$, Andrew $\mathrm{Chow}^{4}$,

Majed Khraishi ${ }^{5}$, Suneil Kapur ${ }^{6}$, Michel Zummer ${ }^{7}$, Jon Chan ${ }^{8}$, Larissa Lisnevskaia ${ }^{9}$, Raheem Kherani ${ }^{10}$, Emmanouil Rampakakis ${ }^{11}$, Odalis Asin Milian ${ }^{11}$, Allen Lehman ${ }^{11}$, Meagan Rachich ${ }^{12}$, Francois Nante ${ }^{11}{ }^{1} .{ }^{1}$ Memorial University of Newfoundland, St. John's, Canada; ${ }^{2}$ University of Saskatchewan, Saskatoon, Canada; ${ }^{3}$ Centre Rhumatologie de l'Est, Rimouski, Canada; ${ }^{4}$ University of Toronto, Toronto, Canada; ${ }^{5}$ Nexus Clinical Research, St. John's, Canada; ${ }^{6}$ University of Ottawa, Ottawa, Canada; ${ }^{7}$ University of Montreal, Montreal, Canada; ${ }^{8}$ Artus Health Centre, Vancouver, Canada; ${ }^{9}$ Oshawa Clinic, Oshawa, Canada; ${ }^{10}$ University of British Columbia, Richmond, Canada; ${ }^{11}$ Janssen Inc, Toronto, Canada; ${ }^{12} \mathrm{Janssen}$ Inc., Toronto, Canada

Background: Long-term registries are essential to evaluate new therapies in a patient population that differs from clinical trials and usually varies over time.

Objectives: To describe the profile of psoriatic arthritis (PsA) patients selected for treatment with infliximab (IFX), golimumab (GLM) or ustekinumab (UST) treatment in Canadian routine care and to describe the longterm real-world effectiveness and safety of these agents.

Methods: 462 PsA patients treated with IFX, GLM or UST were enrolled into the Biologic Treatment Registry Across Canada (BioTRAC) registry between 2006-2015, 2010-2017 and 2014-2017, respectively. Study visits occurred at baseline and every 6 months thereafter. Effectiveness was assessed with changes in TJC28, SJC28, skin, enthesitis, dactylitis, pain, $H A Q$, acute phase reactants. Safety was evaluated with the incidence of adverse events (AEs) and drug survival rates.

Results: Of the 111 IFX-, 281 GLM- and 70 UST-treated patients, the proportion of males were $52.3 \%, 46.3 \%$ and $37.1 \%$, the mean age was 48.4, 52.8 and 53.1 years and the mean disease duration was 5.8, 6.1 and 5.7 years, respectively. Most patients were bio-naive $(85.6 \%, 77.9 \%$ and $55.7 \%$ for IFX, GLM and UST, respectively $(p<0.001)$. A reduction in mean baseline duration of morning stiffness was observed in the IFX cohort (from 69.8 to 42.6 to $23 \mathrm{~min}$ in 2006-2008 to 2009-2012 to 20132015; $\mathrm{p}=0.003$ ). Most other baseline disease parameters remained similar over time in all three cohorts. However, UST-treated patients had lower mean baseline DAS28 CRP (3.4 vs 3.9; $p=0.0031)$, SJC (3.8 vs 5.3; $\mathrm{p}=0.0046$ ) and higher PASI (4.8 vs $2.2 ; \mathrm{p}=0.0061$ ) compared to patients treated with GLM

Treatment with IFX, GLM and UST was associated with significant improvements in all disease parameters over time $(P<0.001)$ from baseline up to 84,84 and 40 months, respectively with similar efficacy between agents. The only exception was the proportion of patients in minimal disease activity at 12,24 and 36 months which reached $40.7 \%$, $50.0 \%$ and $55 \%$ in IFX-patients; $64.7 \%, 68.8 \%$ and $78.9 \%$ in GLMpatients and $58.8 \%, 60.0 \%$ and $83.3 \%$ in UST-patients $(\mathrm{p}=0.004$ and $\mathrm{p}<0.001$ vs IFX).

AEs were reported for $74.8 \%, 69.8 \%$ and $52.9 \%(138,114$ and 115 events $/ 100$ PYs) and SAEs for $19.8 \%, 8.5 \%$ and $5.7 \%(8.8,19.6$ and 28.6 events/100 PYs) covering 325, 567 and 87 years of exposure for IFX-, GLM- and UST-treated patients, respectively. One, one and no death occurred IFX-, GLM- and UST-treated patients, respectively. The proportion of patients who discontinued treatment were $63.1 \%, 50.9 \%$ and $50.0 \%$ over a mean exposure of $2.9,1.9$ and 1.2 years to IFX, GLM and UST, respectively.

Conclusion: Differences in baseline characteristics between patients treated with an anti-TNF over an anti-IL12/23 agent suggest that the level of joint to skin involvement might be driving physician choice when the time comes to choose a biologic agent. IFX, GLM and UST treatment significantly reduced disease activity and improved functionality in a similar fashion and were well tolerated in patients with PsA.

Disclosure of Interests: : Proton Rahman: None declared, Regan Arendse Grant/research support from: Janssen Sponsored Study, Isabelle Fortin Grant/research support from: ABBVIE, AMGEN, ASTRAZENECA, BMS, CELGENE, GSK, JANSSEN, PFIZER, SANOFI, UCB, Consultant for: LILLY, NOVARTIS, SANOFI, Speakers bureau: NOVARTIS, PFIZER, Andrew Chow Grant/research support from: Abbvie, Celgene, EliLilly, GSK, Janssen, Novartis, Pfizer, UCB, Consultant for: Abbvie, BMS, Celgene, EliLilly, GSK, Janssen, Novartis, Pfizer, Roche,UCB, Speakers bureau: Abbvie, BMS, EliLilly, Janssen, Novartis, Pfizer, Majed Khraishi Grant/research support from: Novartis, Consultant for: Amgen, Celgene, Gebro, Janssen, Novartis, Pfizer, Lilly, Merck, Suneil Kapur Grant/ research support from: Abbvie, Merck, Janssen, Novartis, Eli Lilly, Amgen, Michel Zummer: None declared, Jon Chan Grant/research support from: Janssen, UCB, Novartis, Pfizer, Celgene, Consultant for:
Amgen, Celgene, Eli Lilly, Janssen, Amgen, Abbvie, Novartis, Pfizer, UCB, Sandoz, Merck, Larissa Lisnevskaia Grant/research support from: Janssen Sponsored Study, Raheem Kherani Grant/research support from: Janssen, BMS, Abbvie, Consultant for: Abbvie, Amgen, BMS, Janssen, Lilly, Merck, Pfizer, Roche, Speakers bureau: Jannsen, BMS, Emmanouil Rampakakis : None declared, Odalis Asin Mlilan Employee of: Employee of Janssen, Allen Lehman Employee of: Employee of Janssen, Meagan Rachich Shareholder of: Janssen, Employee of: Employee of Janssen, Francois Nantel Shareholder of: Janssen, Employee of: Employee of Janssen

DOI: 10.1136/annrheumdis-2019-eular.1440

\section{SAT0394 POSSIBLE POTENTIAL INTERACTIONS BETWEEN OBESITY, QUALITY OF LIFE, PSYCHOLOGICAL STATUS AND CLINICAL PARAMETERS IN PSORIATIC ARTHRITIS}

Kevser Gok ${ }^{1}$, Kemal Nas ${ }^{2}$, Erkan Kilic ${ }^{3}$, Betul Sargin ${ }^{4}$, Sevtap Acer Kasman ${ }^{5}$, Hakan Alkan ${ }^{6}$, Nilay Sahin ${ }^{7}$, Gizem Cengiz ${ }^{8}$, Nihan Cuzdan ${ }^{9}$, Ilknur Albayrak Gezer ${ }^{10}$, Dilek Keskin ${ }^{11}$, Cevriye Mülkoğlu ${ }^{12}$, Hatice Resorku ${ }^{13}$, İsmihan Sunar ${ }^{14}$, Ajda Bal Hasturk ${ }^{15}$, Mehmet Tuncay Duruöz ${ }^{5}$, Okan Kucukakkas ${ }^{16}$, Ozan Volkan Yurdakul ${ }^{16}$, Meltem Alkan Melikoglu ${ }^{17}$, Yildiray Aydin ${ }^{2}$, Figen Ayhan ${ }^{12}$, Hatice Bodur ${ }^{18}$, Mustafa Calis ${ }^{8}$, Erhan Capkin ${ }^{19}$, Gul Devrimse ${ }^{20}$, Sami Hizmetli ${ }^{21}$, Ayhan Kamanli ${ }^{2}$, Yasar Keskin ${ }^{16}$, Hilal Kocabas ${ }^{22}$, Oznur Kutluk ${ }^{23}$, Nesrin Sen ${ }^{24}$, Omer Faruk Sendur ${ }^{25}$, Ibrahim Tekeoğlu ${ }^{26}$, Murat Toprak ${ }^{27}$, Sena Tolu ${ }^{16}$, Tiraje Tuncer ${ }^{23} .{ }^{1}$ Ankara Numune TraiandRes Hospt, Ankara, Turkey, ${ }^{2}$ Sakarya Unv, Sakarya, Turkey, ${ }^{3}$ Afyon Hospt, Afyon, Turkey; ${ }^{4}$ Aydin Hospt, Aydin, Turkey; ${ }^{5}$ Marmara Unv, Istanbul, Turkey, ${ }^{6}$ Pamukkale Unv, Denizli, Turkey, ${ }^{7}$ Balikesir Unv, Balikesir, Turkey, ${ }^{8}$ Erciyes Unv, Kayseri, Turkey; ${ }^{9}$ Sanliurfa TraiandRes Hosptl, Sanliurfa, Turkey, ${ }^{10}$ Selçuk Unv, Konya, Turkey; ${ }^{11}$ Kirikkale Unv, Kirikkale, Turkey, ${ }^{12}$ Ankara TraiandRes Hospt, Ankara, Turkey, ${ }^{13}$ Onsekiz Mart Unv, Canakkale, Turkey; ${ }^{14}$ Ankara Unv, Ankara, Turkey, ${ }^{15}$ Diskapi TraiandRes Hospt, Ankara, Turkey; ${ }^{16}$ Bezmiâlem Unv, Istanbul, Turkey; ${ }^{17}$ Atatürk Unv, Erzurum, Turkey; ${ }^{18}$ Yildirim Beyazit Unv, Ankara, Turkey, ${ }^{19}$ Karadeniz Technical Unv, Trabzon, Turkey; ${ }^{20}$ Recep Tayyip Erdoğan Unv, Rize, Turkey, ${ }^{21}$ Cumhuriyet Unv, Sivas, Turkey; ${ }^{22}$ Necmettin Erbakan Unv, Konya, Turkey, ${ }^{23}$ Akdeniz Unv, Antalya, Turkey, ${ }^{24}$ Kartal Dr. Lütfi Kirdar TraiandRes Hosptl, Istanbul, Turkey; ${ }^{25}$ Adnan Menderes Unv, Aydin, Turkey, ${ }^{26}$ SakaryaUnv, Sakarya, Turkey, ${ }^{27}$ Yuzuncu Yil Unv, Van, Turkey

Background: Psoriatic arthritis (PsA), a chronic rheumatic disease associated with reduced quality of life. Obesity is an important clinical problem which may interfere with loss of functioning and quality of life. Obesity is usually an overlooked entity in patients with PsA. Several studies were invastigated prevalence and the impact of obesity on disease activity in patients with PsA, however relationship between psychological status and quality of life have not been evaluated comparatively.

Objectives: To assess the impact of obesity on quality of life, psychological status and clinical parameters in patients with PsA.

Methods: Patients with PsA were recruited who met CASPAR classification criteria enrolled by Turkish League Against Rheumatism-NETWORK (TLAR-NETWORK) derived from 24 different centers of our country. Patients with $\mathrm{BMI} \geq 30 \mathrm{~kg} / \mathrm{m}^{2}$ were considered obese. Differences among patients with or without obesity were assessed.VAS fatigue, psychological status and health related quality of life measures [SF-36; HAQ; Psoriatic arthritis quality of life (PSAQoL); Hospital Anxiety and Depresson Scale] FACIT-Fatigue, DAS28, BASDAI, BASFI, BASMI, Maastrich Ankylosing Spondylitis Enthesitis Score (MASES) and Psoriasis area severity index (PASI) scores were compered between this groups.

Results: A total 1130 patients with PsA (36.0\% male, $64.0 \%$ female) included in this study. In this cohort $37.6 \%$ obese and $62.4 \%$ non-obese The presence of peripheral arthritis, enthesitis, dactylitis, uveitis and spine involvement, PASI scores as well as MASES scores were quite similar between patients with and without obesity. Obese patients had significantly higher scores in VAS fatigue and disease activity, poorer QoL and physical functions compared to non-obese patients $(p<0.05)$. Obese patients had high risk for anxiety and depression $(p<0.05)$.

Conclusion: Obesity associated with the risk of depression and anxiety, fatigue, poorer QoL and higher disease activity.These findings suggest that obesity should be considered while assessing patients with PsA.

\section{REFERENCES}

[1] Li W,Han J,Qureshi AA.Obesity and risk of incident psoriatic arthritis in US women.Ann Rheum Dis.2012Aug;71(8):1267-72.

[2] Klingberg E,Bilberg A,Björkman $S$, et al.Weight loss improves disease activity in patients with psoriatic arthritis and obesity:an interventional study.Arthritis Res Ther.2019Jan11;21(1):17 